\title{
Analysis of Antimicrobial Properties of PVA-Based Coatings with Silver and Zinc Oxide Nanoparticles
}

\author{
Jolanta Pulit-Prociak ${ }^{1} \cdot$ Anita Staroń ${ }^{1} \cdot$ Magdalena Prokopowicz $^{1} \cdot$ Karolina Magielska $^{1} \cdot$ Marcin Banach $^{1}$
}

Received: 29 August 2020 / Accepted: 3 December 2020 / Published online: 14 April 2021

(c) The Author(s) 2021

\begin{abstract}
Public places such as swimming pools, saunas and jacuzzis are at high risk of developing microorganisms and are a potential source of disease. Above all, increased temperature and humidity favour this. A relatively new but effective way to combat microorganisms is to subject them to metal or metal oxide nanoparticles. The paper presents a method of obtaining nanocompositions for direct application at the place of occurrence of the microorganisms. The advantage of nanocompositions is that they can easily be removed from the infected surface in the form of a film containing dead organic matter. The article investigates the biocidal properties against common microorganisms such as Aspergillus niger and Candida albicans of nanocompositions containing silver nanoparticles and nanometric zinc oxide. The physicochemical properties of the nanocompositions were characterised and the antifungal properties of the preparations obtained determined using the suspension method. The results showed that the PVA-based compositions obtained were able effectively to inhibit the growth of the tested strains. Elongation of contact time between microorganism and nanoparticles which was changed from 5 to $60 \mathrm{~min}$ resulted in higher antimicrobial activity. It was manifested in reduced growth area. The same observation was made when the concentration of used nanoparticles was increased. When the concentration of nanosilver raised from 12.5 up to $200 \mathrm{ppm}$, the development of Aspergillus niger was slower. Increasing of zinc oxide nanoparticles concentration resulted in growth inhibition of Candida albicans strain.
\end{abstract}

Jolanta Pulit-Prociak

jolanta.pulit-prociak@pk.edu.pl;

jolantapulit@chemia.pk.edu.pl

Anita Staroń

anita.staron@pk.edu.pl

Magdalena Prokopowicz

mprokopowicz97@gmail.com

Karolina Magielska

magielska.karolina@gmail.com

Marcin Banach

marcinbanach@chemia.pk.edu.pl

1 Faculty of Chemical Engineering and Technology, Institute of Chemistry and Inorganic Technology, Cracow University of Technology, Warszawska 24, 31-155 Cracow, Poland 


\section{Graphic Abstract}
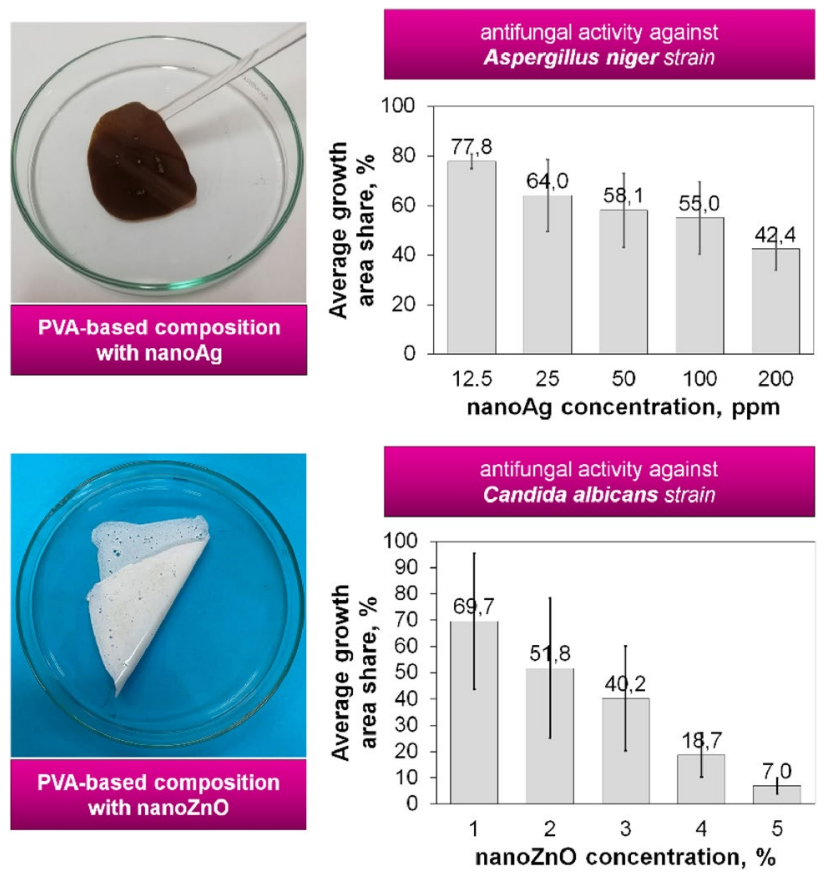

Keywords Nanosilver $\cdot$ Zinc oxide $\cdot$ Nanocompositions $\cdot$ Aspergillus niger $\cdot$ Candida albicans

\section{Introduction}

The increase in the frequency of diseases caused by fungi is due to the easy and quick reproduction of these microorganisms. Their pathogenic activity causes various types of infections on the skin surface, in internal tissues and blood, and can also take the form of systemic mycosis. It is estimated that more than 1.5 million to over a billion people are killed by diseases caused by fungi [1]. Places where there is high humidity and elevated temperature constitute favourable environments for the development of these microorganisms. Such places include swimming pools, saunas, jacuzzis and other public places.

Aspergillus niger is a common fungus around the world. It is commonly called the Black mould and is a mould fungus considered to be one of the most toxic found in nature. Aspergillus niger has the ability to create fibres, so its structure resembles that of a plant and is distinguished by the dark brown colour of its spores [2,3]. The rapid development of A. niger mycelia depends on temperature, environmental $\mathrm{pH}$, water content and percentage relative humidity. The temperature for fungal growth ranges from 6 to $47^{\circ} \mathrm{C}$, but the most favourable temperature is $35-37^{\circ} \mathrm{C}$. Mildew develops best in a slightly acidic environment $(\mathrm{pH}$ around 6.0 ) with increased humidity $[4,5]$. Aspergillus is toxic to the environment by interfering with the functioning of plants and animals. Toxins produced by Aspergillus cause damage to internal organs in animals. They attack the lungs, the liver, the circulatory system and, above all, the heart. The impact and reproduction of toxins in animals is a common cause of death $[6,7]$. The harmful effect of the fungus on the human body is based mainly on its ability to produce toxic substances, pathogens and to cause allergic reactions. During breathing, the human body introduces fungal spores into the respiratory system. Allergies are caused by hyphae, conidia and mould spores formed by asexual reproduction of the fungus [8-10].

A number of serious human and animal diseases are also caused by Candida. Some Candida species may be strong pathogens that cause a number of diseases, including painful superficial infections such as vaginitis in healthy women, and severe oral and oesophageal infections in immunocompromised patients. Candida albicans is the most pathogenic fungus appearing in the human body, and the one most often causing superficial fungal infections. The $C$. albicans strain has 178 antigens, which explains the occurrence of immunological cross-reactions with antigens of various yeasts and moulds as well as antigens of human tissues $[11,12]$.

Treatment of fungal infections usually involves the use of a suitable pharmaceutical. Due to the huge scale of occurrence of pathogenic microorganisms, the best solution seems to be prevention of infections by direct control of 
microorganisms in the place of their occurrence. According to current trends in science and technology, the use of nanomaterials is an effective method of combating microorganisms. Nanocompositions are very popular due to their mechanical, optical, electrical and thermal properties, which are much better than those of traditional compositions. The improved properties are related to, among others, the increased interaction surface between the components of the composition and the specific properties of the nanocomponents $[13,14]$. The biocidal properties of silver nanoparticles and nanometric zinc oxide, which result from damage to the bacterial cell membrane caused by these nanoparticles, have been widely described in the literature. This damage leads to a disruption of the electron transport chain and thus a metabolic disorder [15]. In addition, nanoparticles can accumulate within the bacterial cell membrane, causing an increase in its permeability and cell death [16]. As a result of oxidative stress, damages to lipids, proteins, carbohydrates and DNA may occur [17], lipid peroxidation being the most significant process in the disruption of cellular function [18].

Different fillers using in the functionalization of properties of various polymer matrixes are described in the literature. Rag Son et al. provided the studies on the combination of thermally reduced graphene with different types of polyesters such as poly (butylene terephthalate) and poly (tetramethylene ether) glycol. This filler improved the physicochemical properties of the obtained composites [19]. In order to enhance the thermal stability of poly (ortho-toluidine) Reddy et al. proposed the incorporation of either gold or palladium nanoparticles into its structure. Studies have shown that such composites become more crystalline and their electrical conductivity was two times higher than in the case of pure polymer [20]. Embedding of iron oxide $\left(\mathrm{Fe}_{3} \mathrm{O}_{4}\right)$ nanoparticles into the structure of poly (aniline-co-aminonaphthalenesulfonic acid) gave similar results. The pure polymer is characterised by a much lower conductivity in comparison with modified composite [21]. An incorporation of silver nanoparticles in the poly (o-toluidine) matrix gave a hybrid organoinorganic composite material. This resulted in increased electrical conductivity of the as-prepared product [22]. Lee et al. presented very interesting research results. The authors used graphite oxides existing on a various oxidation state as a filler in epoxy resin. Thanks to the presence of such nanoparticles it was possible to achieve an antiflammable effect. The solid remnant char acts as a fire retardant. Thus it is highly desired that the distribution of graphite nanoparticles was homogenous in the whole resin matrix [23]. Khan et al. presented a new method for obtaining a composite of carbon nanotubes combined with poly (styrene). The process resulted in formation of nanostructured brush. Prior of combining carbon nanotubes were functionalized with oleic acid and (3-aminopropyl) triethoxysilane which allowed achieving cross-linking properties. It was confirmed that carbon nanotubes were well integrated with polymer matrix. Thanks to the fact that the prepared material was characterised by a high surface area it is expected that it may be applied in gases separation processes [24]. Another functionalizing processes were performed by Choi et al. [25] and Reddy et al. [26]. Both enhanced electrical conductivity and thermal resistance were achieved in an obtained material. It was possible due to the combination of waterborne polyurethane with functionalized graphene sheets [25].

The literature reports the antifungal activity of metal nanoparticles (silver, copper, gold) and metal oxides (titanium, zinc and magnesium oxides) probably resulting from the disruption of cell membrane continuity [27-30]. Exposure of fungi to nanoparticles reduces the level of antioxidative mechanisms and oxidative enzymes, and disturbs osmotic balance and cellular integrity [31]. Fungicidal effectiveness was confirmed in relation to, among others Cladosporium cladosporioides, A. niger, Colletotrichum gloeosporioides, Erythricium salmonicolor Raffaelea spp., and Candida spp. [32-34].

This paper presents the results of research on the antimicrobial effectiveness of compositions containing silver and zinc oxide nanoparticles. The assumption was that the prepared nanocompositions solidify when applied at the place of occurrence of microorganisms, which will allow the removal from the infected surface of the composition in the form of a film containing dead organic matter. Nanocompositions in the suspension form that are characterized with biocidal properties have been developed. The products have the ability to neutralize biofilm and remove dead biological material. Nanocompositions are dedicated to be used in facilities with increased temperature and humidity, such as recreational or sanitary-hygienic facilities. Their destination may also be infected surfaces in other utility objects. In particular, poly (vinyl alcohol) based nanocomposites were obtained. The biocidal properties of the produced materials were achieved by enriching their structure with metallic nanoparticles (nanoAg) or metal oxide nanoparticles (nano$\mathrm{ZnO}$ ). It is possible to apply the product in the suspension form on a microbiologically infected surface, so that after it solidifies, it can be removed along with dead biological material. PVA has many advantages over other polymers. After application in its liquid form, the PVA-based compositions are able to solidify very quickly. This feature is highly desired when considering the above mentioned application. PVA forms a materials that are characterized by a high biocompatibility. They are also safe for humans. What is more, it is possible to easily embed other crucial substances such as nanoparticles or some organic matter in its structure. Studies have shown that the PVA-based coatings adhere well to most types of surfaces which is also needed. 


\section{Materials and Methods}

\subsection{Materials}

The following compounds were used in this study: poly (vinyl alcohol) $(\mathrm{M}=72 \mathrm{~kg} / \mathrm{mol}, \geq 99.0 \%)$, sucrose $(\geq 99.5 \%)$, 2-hydroxyethyl cellulose ( $M=90 \mathrm{~kg} / \mathrm{mol}$, p.p.a.), guar gum (p.p.a.), gelatine (p.p.a.), chitosan ( $\mathrm{M}=100-300 \mathrm{~kg} / \mathrm{mol}$, high purity), glycerol $(\mathrm{d}=1.26 \times 103 \mathrm{~kg} / \mathrm{m} 3$, p.p.a. $)$, casein (p.p.a.), zinc nitrate ( $\geq 99.9 \%$ ), silver nitrate ( $\geq 99.0 \%)$, tannic acid (ACS reagent), sodium hydroxide $(\geq 98.0 \%)$ and acetic acid $(\geq 99.0 \%)$. All compounds were obtained from Sigma-Aldrich. The strains of A. niger and C. albicans used in the study were taken from the American Type Culture Collection (ATCC). The following compounds were used in the microbiological tests: pancreatic tryptone, sodium chloride ( $\geq 99.5 \%$ ), Dey-Engley neutralising broth, Polysorbate 80 (ACS reagent), yeast extract, soy peptone and agar. All aqueous solutions were prepared using deionised water (Polwater, $0.18 \mu \mathrm{S}$ ).

\subsection{Methods}

\subsubsection{Preparation of PVA-Based Compositions}

Compositions with either silver (A) or zinc oxide (B) nanoparticles were prepared. The compositions are shown in Table 1 . Forty grams of product was obtained with each process.

The processes were conducted in a water bath at $80^{\circ} \mathrm{C}$. All ingredients were dissolved in water with the exceptions of chitosan, which was dissolved $1.5 \%$ of acetic acid and casein, which was dissolved in $3 \mathrm{~mol} / \mathrm{L}$ aqueous sodium hydroxide. Glycerol was added in pure form. The solutions of the components, glycerol and zinc oxide powder were added into the basic aqueous PVA solution. The order of introduction was according to those shown in Table 1 . The reaction mixture was mixed constantly by mechanical stirrer (1000 rpm). After introducing the last ingredient, the composition was mixed for further $10 \mathrm{~min}$ in the case of products containing nanosilver and $30 \mathrm{~min}$ for compositions containing zinc oxide nanoparticles. Silver nanoparticles were obtained in situ during the formation of the product. Tannic acid was used to both reduce the silver ions and to stabilise the nanoparticles formed. Aqueous sodium hydroxide was applied to dissolve casein; as a result, it was not necessary to introduce additional activating factors because sodium hydroxide also played the role of activating the tannic acid used as a reducing agent. Additional steric stabilisation was achieved by applying gelatine, guar gum and hydroxyethyl cellulose. In particular, aqueous silver nitrate solution at a concentration of $0.3708 \mathrm{~mol} / \mathrm{L}$ and aqueous tannic acid solution at a concentration of $0.1855 \mathrm{~mol} / \mathrm{L}$ were prepared. In the process of PVA-based composition formation, equal amounts of both solutions were taken $(0.2 \mathrm{~mL})$. Thus, the molar ratio of tannic acid to silver ions was equal to $0.5: 1.0$.

In the case of Composition B, the zinc oxide nanoparticle powder was prepared according to previously described methods [35, 36]. Initially, zinc oxide nanoparticles were obtained in a separate process. The nanoparticles were formed in a two-step process. In the first step, zinc hydroxide was precipitated by reaction of zinc nitrate with sodium hydroxide. Aqueous solutions of zinc nitrate at a concentration of $0.2 \mathrm{~mol} / \mathrm{L}$ and sodium hydroxide at a concentration of $0.4 \mathrm{~mol} / \mathrm{L}$ were prepared. Then $160 \mathrm{~mL}$ of zinc nitrate solution and $40 \mathrm{~mL}$ of sodium hydroxide solution were mixed in a Parr 4525 pressure reactor to obtain zinc hydroxide. The process of dehydration of zinc hydroxide to zinc oxide was carried out for $30 \mathrm{~min}$ at the temperature of $180^{\circ} \mathrm{C}$. After the end of the process, the obtained nanometric zinc oxide was filtered under reduced pressure on Sartorius Stedim
Table 1 Components of the PVA-based compositions

\begin{tabular}{|c|c|c|c|}
\hline Component & & Composition A & $\begin{array}{l}\text { Com- } \\
\text { posi- } \\
\text { tion B }\end{array}$ \\
\hline PVA, $\%$ & & 7 & \\
\hline Sucrose, $\%$ & & 0.12 & \\
\hline Hydroxyethyl cellulose, \% & & 0.1 & \\
\hline Guar gum, \% & & 0.05 & \\
\hline Gelatine, $\%$ & & 0.1 & \\
\hline Chitosan, $\%$ & & 0.01 & \\
\hline Glycerol, \% & & 14.0 & \\
\hline $\begin{array}{l}\text { Silver nitrate, } 0.3708 \mathrm{~mol} / \mathrm{L}, 0.2 \mathrm{~mL} \\
\text { Tannic acid, } 0.1855 \mathrm{~mol} / \mathrm{L}, 0.2 \mathrm{~mL}\end{array}$ & nanoAg, ppm & 200 & - \\
\hline Zinc oxide, $\%$ & & - & 5 \\
\hline Casein, \% & & 0.4 & \\
\hline
\end{tabular}


nitrate-cellulose filters with a pore diameter of $0.45 \mu \mathrm{m}$. The solid was washed several times with deionized water to rinse out the nitrate and sodium ions, and after the filtration was completed, the product was left to dry at $110^{\circ} \mathrm{C}$, and then triturated in an agate mortar. As obtained powder of zinc oxide nanoparticles was taken to the process of PVAbased nanocomposition formation. The concentrations and amounts of the introduced solutions were chosen so that the final concentrations of the individual ingredients were equal to the values shown in Table 1 .

In the obtained compositions, $\mathrm{pH}$, density, size of nanosilver particles and their electrokinetic potential were determined. The $\mathrm{pH}$ was measured with using an Elmetron $\mathrm{pH}$ electrode, density by means of weighing methods, and the size of nanosilver particles by dynamic light scattering (DLS) (Zetasizer Nano, Malvern). Identification of silver nanoparticles in the obtained compositions was carried out using the UV-Vis method (UV 1800, Rayleigh). The DLS method also served to assess the electrokinetic potential, which defines the stability of the particles. The presence of both silver and zinc oxide nanoparticles in the solidified compositions, as well as their distributions, were examined by scanning electron microscopy (SEM) with energy-dispersive X-ray spectrometry (EDX; 1430 VP microscope, LEO Electron Microscopy). The solid compositions were also examined by FT-IR (Nicolet 380 spectrophotometer, Thermo Fisher). The crystal structure of the solidified composition containing zinc oxide nanoparticles was determined by X-ray diffractometry (XRD; X'Pert PW 1752/00, Philips).

\subsubsection{Analysis of Antimicrobial Properties}

The antimicrobial properties of both products were assessed according to the Polish Standard PN-EN 1650 [37].

Tested suspensions of $C$. albicans and A. niger strains were used in the studies. The activity of composition with silver nanoparticles was assessed against $A$. niger and the composition with zinc oxide nanoparticles was tested as an agent against $C$. albicans. In order to prepare the starting test suspension of $C$. albicans, a pinch of initial cultivation of microorganisms was suspended in a mixture of $90 \mathrm{~mL}$ of autoclaved water and $10 \mathrm{~mL}$ of diluting agent. The starting tested suspension of $A$. niger was prepared by introducing a pinch of initial cultivation of microorganisms into a mixture consisted of $90 \mathrm{~mL}$ of autoclaved water and $10 \mathrm{~mL}$ of autoclaved Polysorbate 80 solution at a concentration of $0.05 \%(\mathrm{w} / \mathrm{v})$. The starting tested suspensions were shaken for $3 \mathrm{~min}$. After this time, the concentration of microorganisms was measured using a Fuchs-Rosenthal chamber by microscopy. When using an autoclaved diluting agent, the tested suspensions of microorganisms were so dilute that the final concentrations in the suspensions were in the range $(1.5-5.0) \times 10^{7} \mathrm{cfu} / \mathrm{mL}$. One litre of diluting agent consisted of $1.0 \mathrm{~g}$ of pancreatic tryptone, $8.5 \mathrm{~g}$ of sodium chloride and autoclaved water.

Both compositions were diluted with deionised water so that the final concentration of silver nanoparticles were 12.5, 25,50 and $100 \mathrm{ppm}$ and $1 \%, 2 \%, 3 \%$, and $4 \%$ in the case of zinc oxide nanoparticles. Dey-Engley neutralising agent was also prepared by dissolving $39 \mathrm{~g}$ of Dey-Engley compound in $1000 \mathrm{~mL}$ of water and then autoclaving.

The next step of the procedure was to put $8 \mathrm{~mL}$ of testing material (PVA-based composition at different nanoparticle concentrations), $1 \mathrm{~mL}$ of autoclaved water and $1 \mathrm{~mL}$ of test suspension of microorganisms (A. niger or C. albicans) into autoclaved tubes. The tubes were shaken for a specific time: 5, 15, 30 or $60 \mathrm{~min}$. After this specific time, $1 \mathrm{~mL}$ of analysed suspension was taken and introduced into the previously prepared tube with neutralising agent $(8 \mathrm{~mL})$ and autoclaved water $(1 \mathrm{~mL})$. The tubes were shaken vigorously. The neutralisation processes took $5 \mathrm{~min}$. After this time, $1 \mathrm{~mL}$ of suspension was placed onto a Petri dish previously prepared with solid medium. In both microorganism strains, the growth medium consisted of pepton $(8.0 \mathrm{~g})$, yeast extract $(4.0 \mathrm{~g})$, sucrose $(8.0 \mathrm{~g})$, agar $(8.0 \mathrm{~g})$ and water (up to $400 \mathrm{~mL}$ ). The dishes were incubated in $30^{\circ} \mathrm{C}$ for 24,48 and $72 \mathrm{~h}$. After this time the cultivations were evaluated and the share of growth area assessed. Pure water was used as the test agent in the reference sample.

\section{Results and Discussion}

\subsection{PVA-Based Compositions}

Solidified PVA-based compositions with silver (A) and zinc oxide (B) nanoparticles are shown in Fig. 1. The brown colour of the nanosilver composition was visual proof of the presence of $\mathrm{Ag}$ nanoparticles. The intensity of the colour was consistent with a silver concentration of $200 \mathrm{ppm}$. The presence of zinc oxide nanoparticles was indicated by the white colour of the composition.
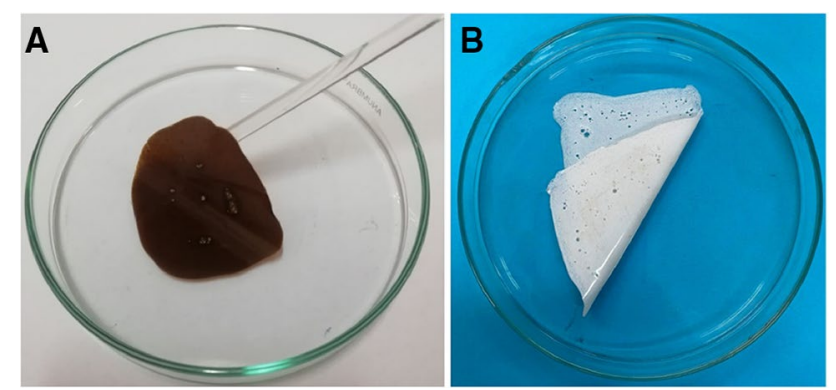

Fig. 1 PVA-based compositions with silver (a) and zinc oxide (b) nanoparticles 
The $\mathrm{pH}$ values of the obtained compositions were $6.1 \pm 0.2$ (for composition with nanoAg) and $7.0 \pm 0.1$ (for composition with nanoZnO). The density of the composition is a crucial factor in the context of its application to a microbiologically contaminated surface. The composition with silver nanoparticles had a density of $1.27 \pm 0.05 \mathrm{~g} / \mathrm{mL}$. Due to the fact that the second product contained zinc oxide, its density was greater, at $1.67 \pm 0.17 \mathrm{~g} / \mathrm{mL}$.

Figure 2 shows the UV-Vis spectra of the silver nanoparticle composition. The peak with maximum absorbance at $\lambda=460 \mathrm{~nm}$ corresponds to the plasmon resonance of nanosilver [38, 39]. The proposed mechanism of formation of silver nanoparticles is presented in Fig. 3. In alkaline environment phenolic form of tannic acid is transformed into quinone form. In this process free electrons are released. When contacting with silver ions they reduce them into zero oxidation state. Thus formation of metallic silver starts

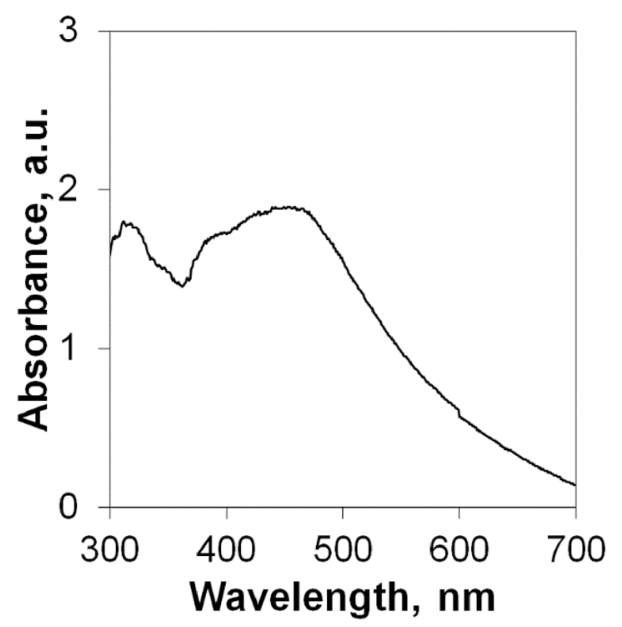

Fig. 2 UV-Vis UV-vis spectra of nanoAg composition (50 ppm) occurring. Both tannic acid and the rest of organic matter which is present in the reaction system play the role of the stabilizing agents. By adsorbing on the nanosilver surface they inhibit their further agglomeration.

The size of silver nanoparticles was determined by DLS. Prior to analysis, the silver nanoparticle composition was diluted with water to $50 \mathrm{ppm}$. It was found that $55.3 \%$ of particles had a size of $259 \mathrm{~nm}$ and the mean size of the rest was $26 \mathrm{~nm}$. The electrokinetic potential $\xi$ determines the stability of the nanoparticles. It is assumed that if the absolute value of the electrokinetic potential is greater than $20 \mathrm{mV}$ then the tested system is stable. The electrokinetic potential of the composition containing silver nanoparticles was $19.2 \pm 0.1 \mathrm{mV}$; therefore, the tested product exhibited moderate stability.

Figure 4 presents the diffractogram of the solid composition with zinc oxide nanoparticles (5\%), from which the presence of zinc oxide may be identified. The presence of $2 \theta$ reflections at $31.6^{\circ}, 34.4^{\circ}, 36.1^{\circ}, 47.6^{\circ}$ and $56.6^{\circ}$ are characteristic for zinc oxide [40-42], while $2 \theta$ peaks at $19.5^{\circ}$ and $40^{\circ}$

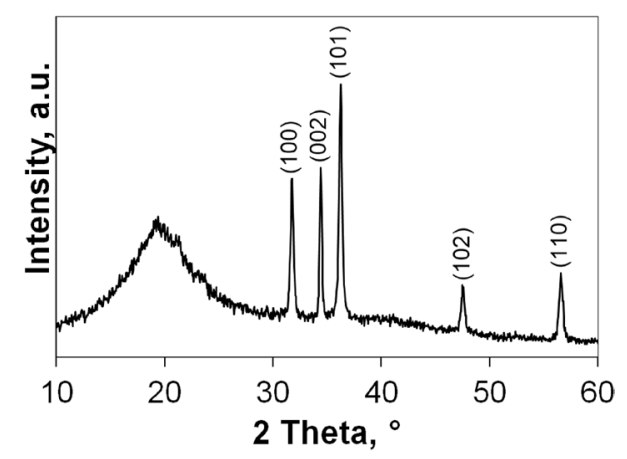

Fig. 4 XRD diffractogram of PVA-based coating with zinc oxide nanoparticles
Fig. 3 Schematic mechanism of silver nanoparticles formation<smiles>[R]c1cc(=O)c(=O)c(=O)c1=O</smiles> 
correspond to the semi-crystalline and amorphous phases of PVA [43]. Their intensity, especially at around a $2 \theta$ angle of $20^{\circ}$ may be enhanced by other organic matter [44-49]. The mechanism of zinc oxide nanoparticles formation is provided in Eqs. 1 and 2. In the first stage of the process zinc hydroxide is precipitated. The reaction mixture has been put into the high pressure reactor in which the dehydration process occurred. Thanks to the applying of high temperature and high pressure it was possible to obtain stable nanometric particles.

$$
\begin{aligned}
& \mathrm{Zn}(\mathrm{NO})_{3}+2 \mathrm{NaOH} \rightarrow \mathrm{Zn}(\mathrm{OH})_{2} \downarrow+2 \mathrm{NaNO}_{3} \\
& \mathrm{Zn}(\mathrm{OH})_{2} \stackrel{\Delta}{\longrightarrow} \mathrm{ZnO}+\mathrm{H}_{2} \mathrm{O}
\end{aligned}
$$

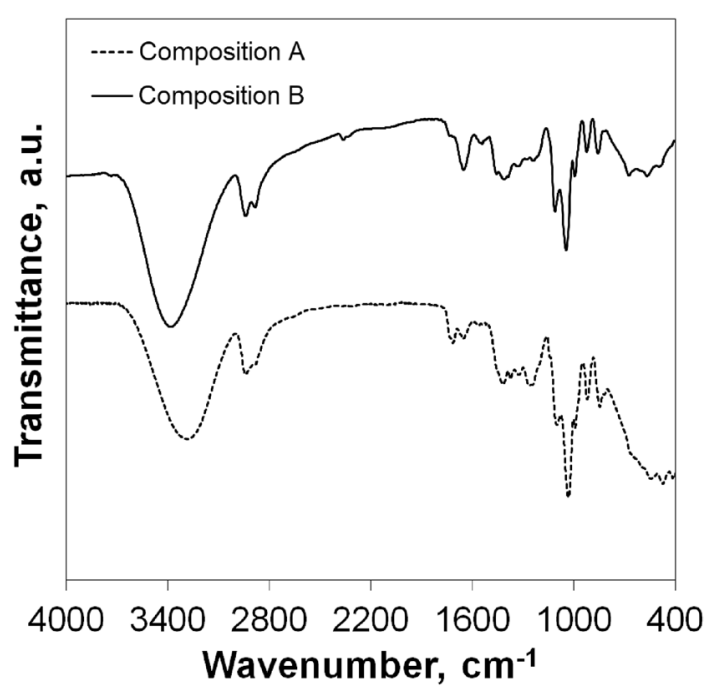

The FTIR spectra of both products are presented in Fig. 5 . The specific wavenumbers at which characteristic absorption bands occur are provided in Table 2. It may be observed that both spectra overlap, which is the proof of matrix similarity. The identified groups are characteristic of the applied organic material. The spectrum of Composition B contains an additional peak at $473 \mathrm{~cm}^{-1}$, which confirms the presence of zinc oxide in the product [50].

Figure 6 presents the results of SEM-EDX studies. The presence of silver and zinc in Compositions A and $\mathrm{B}$, respectively, was confirmed. The EDX spectra contain peaks characteristic of both elements. Elemental analysis also confirmed the organic matter content. The peak at approx. $1.5 \mathrm{keV}$ indicates the presence of aluminum. This element originates from the apparatus background. One may observe that both silver and zinc oxide nanoparticles were well dispersed in the analysed structures. The agglomeration of nanoparticles visible in the SEM microphotography of Composition A are due to insufficient mixing of the liquid composition prior to its solidification.

\subsection{Antimicrobial Properties}

The results of analysis of antimicrobial properties of both compositions are presented in Figs. 7 and 8. The activities of the composition with silver nanoparticles against $A$. niger (Fig. 6a) and the composition with zinc oxide nanoparticles against $C$. albicans (Fig. 6b) were monitored after 24, 48 and $72 \mathrm{~h}$ of incubation. The growth area measured for reference sample was always treated as $100 \%$.

The antifungal activity of the composition with nanosilver was manifest in that an increase in its contact time with

Fig. 5 FTIR spectra of obtained compositions

Table 2 Identification of functional groups in FTIR spectra $[44,50-58]$

\begin{tabular}{lll}
\hline $\begin{array}{l}\text { Wavenumber, } \mathrm{cm}^{-1} \text { (Composi- } \\
\text { tion A) }\end{array}$ & $\begin{array}{l}\text { Wavenumber, } \mathrm{cm}^{-1} \text { (Composi- } \\
\text { tion B) }\end{array}$ & Identified group \\
\hline 3367 & 3291 & $\mathrm{O}-\mathrm{H}$ stretching vibration \\
2937 & 2931 & $\mathrm{CH}_{2}$ asymmetric vibration \\
1695 & 1714 & $\mathrm{C}=\mathrm{O}$ carbonyl stretch \\
1649 & 1654 & $\mathrm{C}=\mathrm{O}$ stretching vibration of amide I \\
1241 & 1540 & $\mathrm{~N}-\mathrm{H}$ bending vibration of amide II \\
1423 & 1419 & $\mathrm{CH}_{2}$ symmetric bending \\
1321 & 1320 & $\mathrm{CH}$ deformation vibration \\
1232 & 1243 & $\mathrm{CH}$ band \\
1064 & 1063 & $\mathrm{CO}$ stretching of acetyl groups \\
1041 & 1031 & $\mathrm{CO}$ stretching vibration \\
1018 & 1015 & $\mathrm{CO}$ stretching vibration \\
920 & 919 & $\mathrm{CH}$ rocking vibration \\
852 & 846 & $\mathrm{C}-\mathrm{C}$ stretching vibration \\
669 & 667 & $\mathrm{CH}$ aromatic vibration \\
- & 473 & $\mathrm{Zn}-\mathrm{O}$ vibration band \\
\hline
\end{tabular}



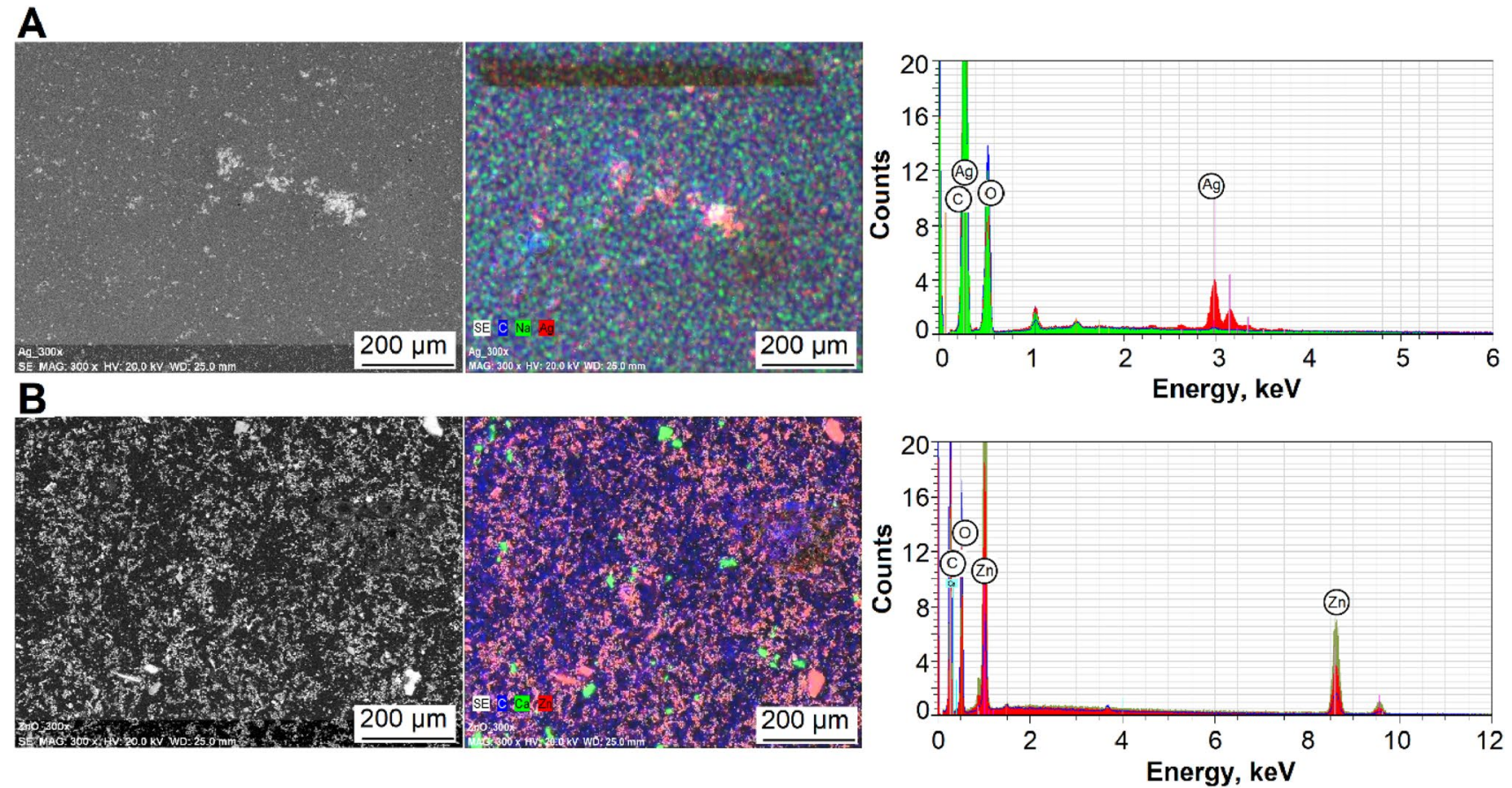

Fig. 6 SEM, mapping and EDX spectra of obtained compositions (a - Composition $\mathbf{a}, \mathbf{b}-$ Composition $\mathbf{b})$

A. niger resulted in weaker development of the tested strain. The highest inhibition rate was observed in up to $30 \mathrm{~min}$ of contact. The difference in inhibition rate between 30 and $60 \mathrm{~min}$ was less significant. This fact results from the polynomial character of the curves. From a technical point of view, this result is appropriate in the context of the solidification properties of the composition. This time $(30 \mathrm{~min})$ is long enough to solidify the liquid product. After its solidification the composition may easily be detached along with the microbiological film. One may observe that a higher concentration of silver nanoparticles in the composition resulted in a reduction in growth of $A$. niger. This observation is in line with predictions. After $24 \mathrm{~h}$ of incubation the activity of Composition A with silver nanoparticles at a concentration of $12.5 \mathrm{ppm}$ was the lowest. However, after $60 \mathrm{~min}$ of contact, compared to the reference sample, the reduction rate was lower by almost $46 \%$ (the growth area share was equal to $54.2 \%)$. The activities of the other compositions with higher concentrations of nanosilver were similar and showed much higher activity than that of the composition with silver at a concentration of $12.5 \mathrm{ppm}$. After a longer time of incubation, one may observe a greater difference in the antifungal activity of the nanosilver compositions. This is due to the fact that the fastest development of $A$. niger occurs after $24 \mathrm{~h}$ if incubation. After $48 \mathrm{~h}$ of incubation the lowest growth area share (18\%) was observed with 60 min contact with A. niger of the $200 \mathrm{ppm}$ nanosilver composition. The $5 \mathrm{~min}$ contact resulted in the dishes being covered with the fungi cultures, which means that this contact time was not enough for significant destruction of the test strain, even with higher concentrations of the active agent. The most reliable results were observed after $72 \mathrm{~h}$ of incubation. Compared to the reference, the other samples exhibited enhanced inhibition of the development of A. niger. The most significant differences were visible after 30 - and 60 min contact times. The best results were achieved when composition with a silver concentration of $200 \mathrm{ppm}$ was applied. Despite the progressive growth of the colony, compared to the reference sample (100\%), the inhibition rates after 60 min contact were higher by $48 \%$ and $71 \%$ when applying 100 ppm and 200 ppm, respectively. Considering all contact times, the average growth area shares are shown in Fig. 7. It is clearly seen that applying the composition containing both types of nanoparticle resulted in reductions in the development zones. Higher concentrations of active agent led to decreased colony growth. Compared to the reference, the composition with nanosilver at a concentration of 200 ppm was more effective by almost $58 \%$.

The weaker development of $C$. albicans was also observed in contact with the zinc oxide composition for longer times. After 48 and $72 \mathrm{~h}$ of incubation the inhibition rate was rather constant at each contact time. This is shown by the less polynomial character of the curves. Considering Fig. 7a, which presents results obtained after $24 \mathrm{~h}$ of incubation, one may conclude that the activity of compositions with zinc oxide nanoparticles exhibited excellent antifungal properties. However, the obtained results are misleading. This is due to the full growth of the strain not being initiated. 
Fig. 7 Antimicrobial properties of compositions with a silver nanoparticles against Aspergillus niger strain and $\mathbf{b}$ zinc oxide nanoparticles against Candida albicans after 24, 48 and $72 \mathrm{~h}$ of incubation
A

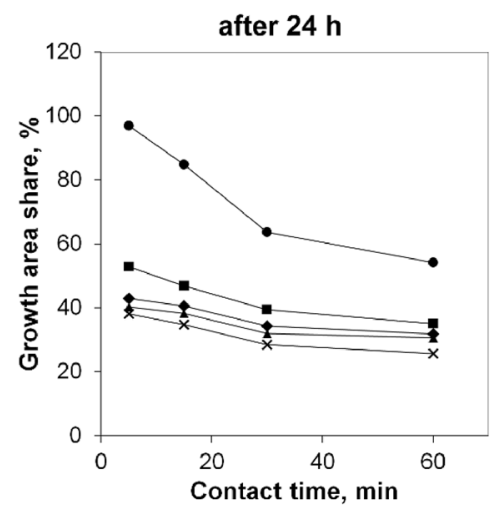

-12.5 ppm $-25 \mathrm{ppm}$ $\bullet 50 \mathrm{ppm}$ $\$ 100 \mathrm{ppm}$ $\times 200$ ppm

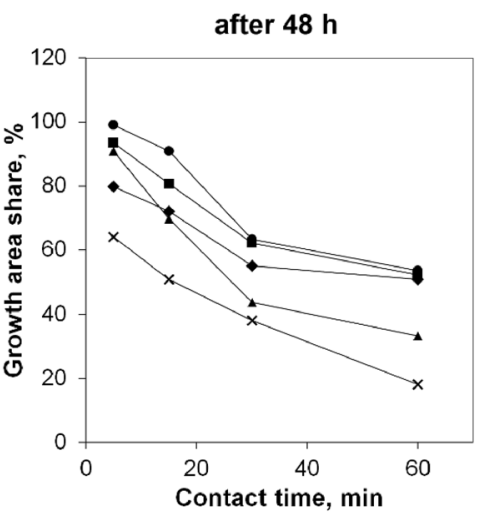

-12.5 ppm - $25 \mathrm{ppm}$ $\checkmark 50$ ppm $+100 \mathrm{ppm}$ *200 ppm
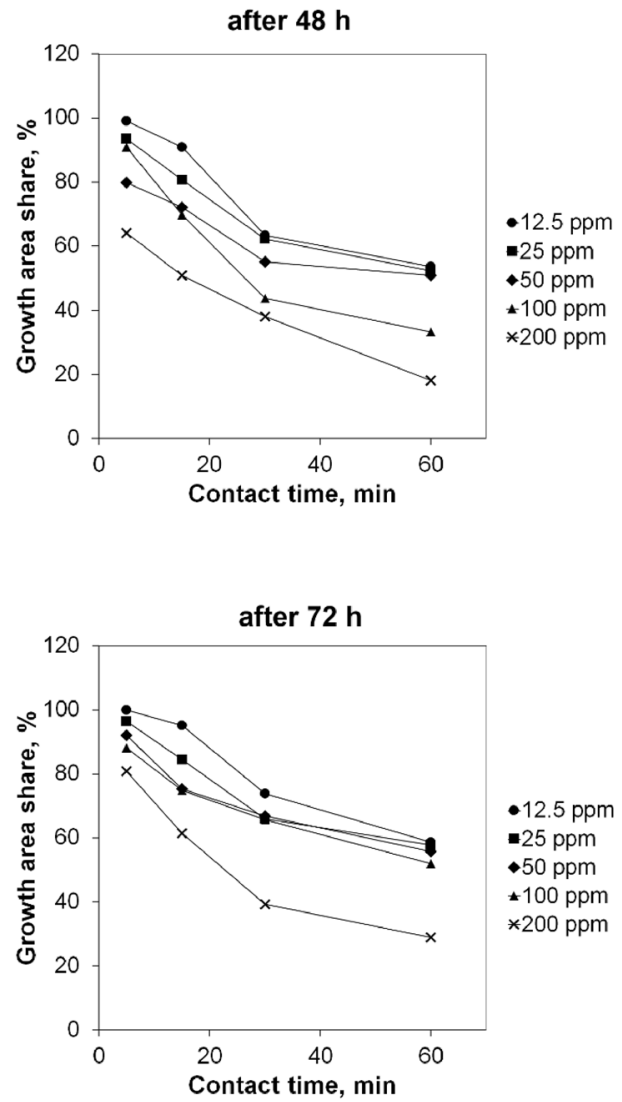

A

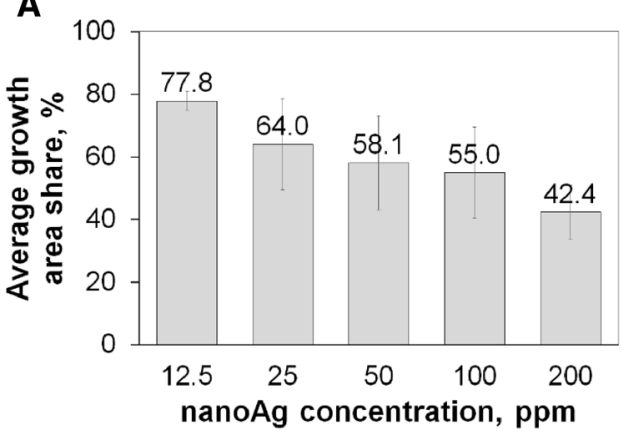

B
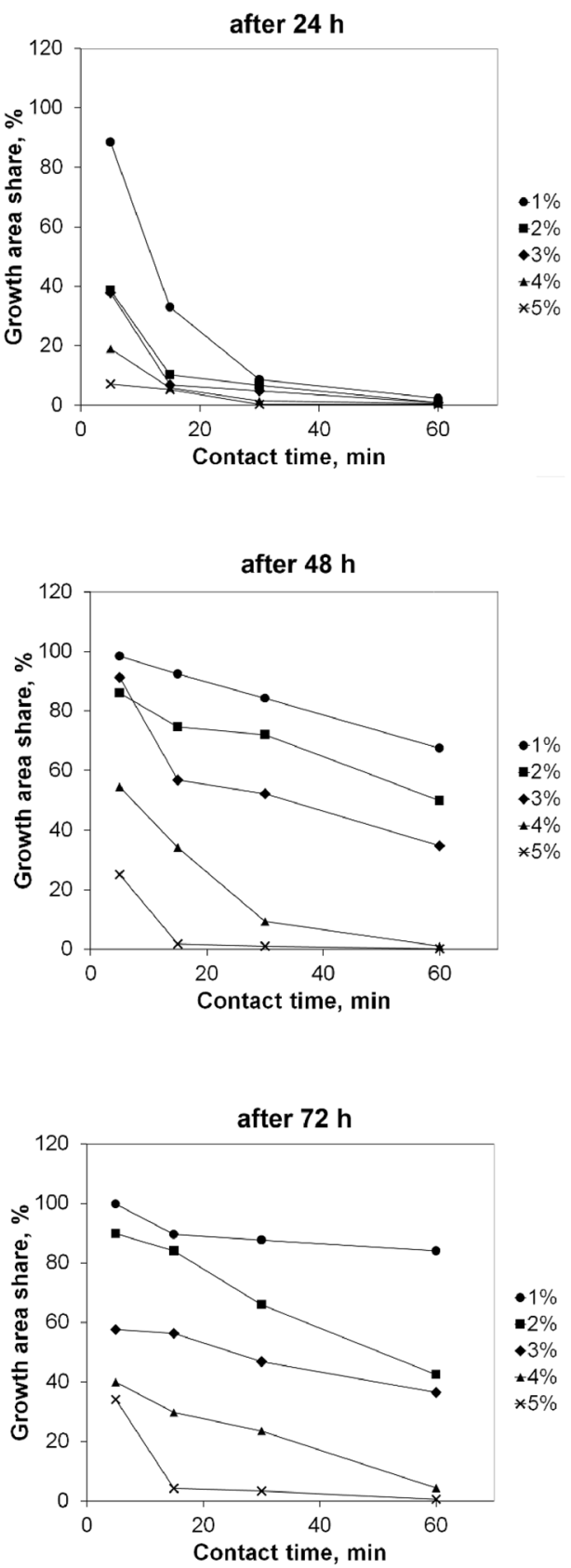

B

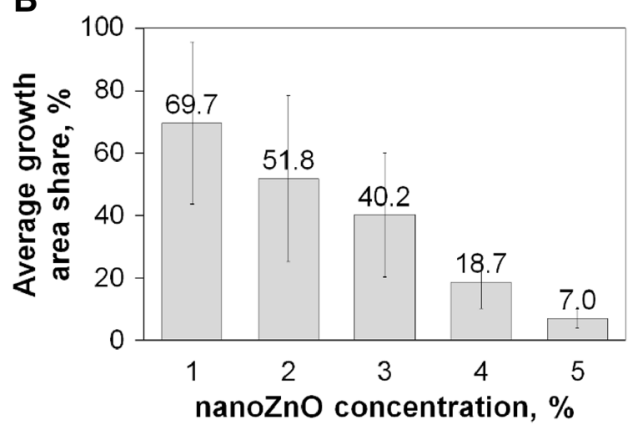

Fig. 8 Average growth area shares for compositions with silver nanoparticles (a) and zinc oxide nanoparticles (b) 
The reference dishes were indeed covered, but the plates were not representative. Only after $48 \mathrm{~h}$ and $72 \mathrm{~h}$ of contact was it possible to assess honestly the antifungal properties of the zinc oxide compositions. Similarly, a higher concentration of zinc oxide resulted in in better antimicrobial activity. The highest destruction activity was achieved by zinc oxide compositions at concentrations of $4 \%$ and $5 \%$, which could be observed even after $15 \mathrm{~min}$. The slight increase in the growth area share observed after $72 \mathrm{~h}$ of incubation was due to the fact that the development of the colonies were of a progressive nature. Nevertheless, almost complete inhibition of the growth of $C$. albicans was maintained. The composition with $1 \%$ zinc oxide content was not able to inhibit efficiently the development of $C$. albicans. Zinc oxide at a concentration of $2 \%$ was better than the reference product by almost $58 \%$ after $60 \mathrm{~min}$ of contact with the test strain. Compared to the reference, the compositions containing zinc oxide nanoparticles at concentrations of $4 \%$ and $5 \%$ ppm were more effective by $81.3 \%$ and $93 \%$, respectively. In general, an increased concentration of zinc oxide resulted in more varied antifungal activity.

The antifungal properties of silver nanoparticles have been assessed by other researchers. Their activity against $A$. niger was evaluated in studies by Essa and Khallaf [59]. The authors examined methods for preventing the microbial contamination of archaeological stones. Nanosilver was incorporated in the structure of sandstone and limestone blocks by mixing it with consolidation polymers. Thanks to that, the development of $A$. niger was rapidly inhibited; $93.8 \%$ of $A$. niger was inhibited by a suspension of silver nanoparticles at a concentration of $40 \mathrm{ppm}$. The minimum concentration necessary to inhibit the growth completely was $60 \mathrm{ppm}$.

In the studies by Naghsh et al. [60] the activity of nanosilver against $A$. niger was assessed. The authors tested various concentrations of silver, i.e., 100, 200, 300, 400 and $500 \mathrm{ppm}$. The concentration that efficiently inhibited the growth of the strain was $150 \mathrm{ppm}$, measured by disc diffusion tests. The authors suggest that the inhibition mechanism of nanosilver may be explained by production of free radicals. Due to their formation, the strain is given to oxidative stress which results in programmed cell death.

Studies have shown that the effectiveness of antimicrobial properties of silver nanoparticles is dependent on different factors. The group of the most important ones includes among others the shape and size of nanoparticles. It was confirmed that both spherical and triangular particles whose size does not exceed $30 \mathrm{~nm}$ destroy the microorganisms in a most effective way [61-66]. Larger particles are not able to effectively penetrate into the cell of bacteria or fungi. What is more, the bacterial strain and cell wall structure play a huge role in the determination of nanoparticles activity [67]. The proper functioning of the respiratory chain in Gram positive bacteria cell wall is conditioned by the presence of peptidoglycans which are located on the cells surface. After contacting with metallic nanoparticles, peptidoglycans lose their properties which are responsible for oxygen respiration which result in death of the microorganism [68]. Hosseini et al. [69] studied the effect of zinc oxide nanoparticles on C. albicans. The average size of the nanoZnO particles was $30 \mathrm{~nm}$, incorporated onto a catheter surface. The formation of the biofilm on the catheters was evaluated. The nanoparticles exhibited very a strong effect in destroying C. albicans, which is a fluconazole-resistant strain. Zinc oxide at a concentration of $50 \mathrm{ppm}$ was able to inhibit formation of biofilm in $100 \%$ fluconazole-resistant isolates.

Talal and Abbas performed in vitro studies on properties of zinc oxide nanoparticles against $C$. albicans isolated from human saliva [70]. The tests were conducted by a disc diffusion method. All tested concentrations of the active agent $(0.01,0.05,0.1,0.5,1,3$ and $5 \mathrm{mg} / \mathrm{mL})$ were strong enough to destroy the strain to various degrees. Also, some other novel materials have been developed in order to ensure the antimicrobial effect [71, 72]. The application of hybrids of metal oxide nanoparticles gives good antimicrobial effect. Besides that, such products may also be used in the field of photocatalysis and some bomedical applications. In the group of valuable metal oxide nanoparticles one may distinguish $\mathrm{TiO}_{2}, \mathrm{NiO}, \mathrm{ZnO}, \mathrm{ZrO}_{2}, \mathrm{WO}_{3}, \mathrm{CuO}$ and iron oxide nanoparticles [73]. The matrix for that oxides may differ. Three basic matrixes matter most. These are ceramic, metallic and polymeric matrixes [74]. Misra et al. synthesized a series of pyrimidine $(8,14,18$ and 23$)$ embellished analogues of 1,5-benzodiazepines. The antibacterial properties of the products were assessed against both Gram positibe and Gram negative bacteria. It was found out obtained products damaged the inerternal structure of bacteria cells which made them not able to stay alive anymore [75]. Also, maleic anhydride may be the base for formation polymers that exhibit antimicrobial properties. These are copolymers/ terpolymers, polymaliamides/maleimides, polymaleats/polyhemiesters and macromolecule with quaternary ammonium groups. Beside antimicrobial effect, they have a great potential to be used in coating systems, water purification systems, drug targeting systems and many others [76].

\section{Conclusions}

It was possible to obtain stable liquid PVA-based compositions with the addition of either silver or zinc oxide nanoparticles. Nanosilver was formed in situ during the formation of the composition, and the composition showed inhibitory properties in the development of Aspergillus niger. The composition containing zinc oxide nanoparticles exhibited destructive activity against Candida albicans. Biocidal effectiveness was determined by the content of nanoparticles 
in the compositions and the time of contact of the microorganism with the composition. Thanks to the use of PVA and other dense and viscous agents, it was possible to apply the liquid form of the compositions easily onto microbiologically contaminated surfaces. After solidification, the composition in coating form may be detached along with the microbial film.

Acknowledgements This research was supported by National Science Centre, Poland (Grant No. UMO-2016/23/D/ST8/00016).

Open Access This article is licensed under a Creative Commons Attribution 4.0 International License, which permits use, sharing, adaptation, distribution and reproduction in any medium or format, as long as you give appropriate credit to the original author(s) and the source, provide a link to the Creative Commons licence, and indicate if changes were made. The images or other third party material in this article are included in the article's Creative Commons licence, unless indicated otherwise in a credit line to the material. If material is not included in the article's Creative Commons licence and your intended use is not permitted by statutory regulation or exceeds the permitted use, you will need to obtain permission directly from the copyright holder. To view a copy of this licence, visit http://creativecommons.org/licenses/by/4.0/.

\section{References}

1. F. Bongomin, S. Gago, R.O. Oladele, D.W. Denning, Global and multi-national prevalence of fungal diseases - estimate precision. J. Fungi 3(4), 57 (2017)

2. A. Gniadek, P. Krzyściak, M. Twaruzek, A.B. Macura, Occurrence of fungi and cytotoxicity of the species: Aspergillus ochraceus, Aspergillus Niger and Aspergillus flavus isolated from the air of hospital wards. Int. J. Occup. Med. Environ. Health 30(2), 231-239 (2017)

3. E. Schuster, N. Dunn-Coleman, J. Frisvad, P. Van Dijck, On the safety of Aspergillus niger - a review. Appl. Microbiol. Biotechnol. 59(4-5), 426-435 (2002)

4. K. Shehu, M. Bello, Effect of environmental factors on the growth of Aspergillus Species associated with stored millet grains in Sokoto. Niger. J. Basic Appl. (2011). https://doi.org/10.4314/ NJBAS.V19I2

5. T.C. Cairns, C. Nai, V. Meyer, How a fungus shapes biotechnology: 100 years of Aspergillus niger research. Fungal Biol. Biotechnol. 5(1), 13 (2018)

6. G. Desoubeaux, C. Cray, Animal models of aspergillosis. Comp. Med. 68(2), 109-123 (2018)

7. D. Elad, E. Segal, Diagnostic aspects of veterinary and human aspergillosis. Front. Microbiol. (2018). https://doi.org/10.3389/ fmicb.2018.01303

8. B. Mousavi, M.T. Hedayati, N. Hedayati, M. Ilkit, S. Syedmousavi, Aspergillus species in indoor environments and their possible occupational and public health hazards. Curr. Med. Mycol. 2(1), 36-42 (2016)

9. M.A. Egbuta, M. Mwanza, O.O. Babalola, Health risks associated with exposure to filamentous fungi. Int. J. Environ. Res. Public Health (2017). https://doi.org/10.3390/ijerph14070719

10. A.K. Gautam, S. Sharma, S. Avasthi, R. Bhadauria, Diversity, pathogenicity and toxicology of A. niger: an important spoilage fungi. Res. J. Microbiol. 6(3), 270-280 (2011)
11. L.E. Jerez Puebla, "Fungal Infections in Immunosuppressed Patients", in immunodeficiency (InTech, Piscataway, 2012).

12. D. Merenstein et al., Colonization by candida species of the oral and vaginal mucosa in HIV-infected and noninfected women. AIDS Res. Hum. Retroviruses 29(1), 30-34 (2013)

13. M. Lyapina, M. Cekova, A. Krasteva, M. Dencheva, M. YanevaDeliverska, A. Kisselova, Physical properties of nanocomposites on relation to their advantages. J. IMAB 22(1), 1056-1062 (2016)

14. P.H.C. Camargo, K.G. Satyanarayana, F. Wypych, Nanocomposites: synthesis, structure, properties and new application opportunities. Mater. Res. 12(1), 1-39 (2009)

15. W.R. Li, X.B. Xie, Q.S. Shi, H.Y. Zeng, Y.S. Ou-Yang, Y. BenChen, Antibacterial activity and mechanism of silver nanoparticles on Escherichia coli. Appl. Microbiol. Biotechnol. 85(4), 1115-1122 (2010)

16. A. Nel, T. Xia, L. Mädler, N. Li, Toxic potential of materials at the nanolevel. Science 311(5761), 622-627 (2006)

17. S.A. Kelly, C.M. Havrilla, T.C. Brady, K.H. Abramo, E.D. Levin, Oxidative stress in toxicology: established mammalian and emerging piscine model systems. Environ. Health Perspect. 106(7), 375-384 (1998)

18. L.E. Rikans, K.R. Hornbrook, Lipid peroxidation, antioxidant protection and aging. Biochim. Biophys. Acta - Mol. Basis Dis. 1362(2-3), 116-127 (1997)

19. D.R. Son, A.V. Raghu, K.R. Reddy, H.M. Jeong, Compatibility of thermally reduced graphene with polyesters. J. Macromol. Sci. 55(11), 1099-1110 (2016)

20. K.R. Reddy, K.P. Lee, A.I. Gopalan, Self-assembly directed synthesis of poly (ortho-toluidine)-metal (gold and palladium) composite nanospheres. J. Nanosci. Nanotechnol. 7(9), 3117-3125 (2007)

21. K.R. Reddy, K.P. Lee, A.I. Gopalan, Novel electrically conductive and ferromagnetic composites of poly (aniline-co-aminonaphthalenesulfonic acid) with iron oxide nanoparticles: synthesis and characterization. J. Appl. Polym. Sci. 106(2), 1181-1191 (2007)

22. K.R. Reddy, K.P. Lee, Y. Lee, A.I. Gopalan, Facile synthesis of conducting polymer-metal hybrid nanocomposite by in situ chemical oxidative polymerization with negatively charged metal nanoparticles. Mater. Lett. 62(12-13), 1815-1818 (2008)

23. Y.R. Lee, S.C. Kim, H. Lee, H.M. Jeong, A.V. Raghu, K.R. Reddy, B.K. Kim, Graphite oxides as effective fire retardants of epoxy resin. Macromol. Res. 19(1), 66-71 (2011)

24. M.U. Khan, K.R. Reddy, T. Snguanwongchai, E. Haque, V.G. Gomes, Polymer brush synthesis on surface modified carbon nanotubes via in situ emulsion polymerization. Colloid Polym. Sci. 294(10), 1599-1610 (2016)

25. S.H. Choi, D.H. Kim, A.V. Raghu, K.R. Reddy, H. Lee, K.S. Yoon, H.M. Jeong, B.K. Kim, Properties of graphene/waterborne polyurethane nanocomposites cast from colloidal dispersion mixtures. J. Macromol. Sci. B 51, 197-207 (2012)

26. K.R. Reddy, H.M. Jeong, Y. Lee, A.V. Raghu, Synthesis of MWCNTs-core/thiophene polymer-sheath composite nanocables by a cationic surfactant-assisted chemical oxidative polymerization and their structural properties. J. Polym. Sci. A Polym. Chem. 48(7), 1477-1484 (2010)

27. S.W. Kim, J.H. Jung, K. Lamsal, Y.S. Kim, J.S. Min, Y.S. Lee, Antifungal effects of silver nanoparticles (AgNPs) against various plant pathogenic fungi. Mycobiology 40(1), 53-58 (2012)

28. N. Cioffi et al., Copper nanoparticle/polymer composites with antifungal and bacteriostatic properties. Chem. Mater. 17(21), 5255-5262 (2005)

29. K.P. Yu, Y.T. Huang, S.C. Yang, The antifungal efficacy of nanometals supported $\mathrm{TiO}_{2}$ and ozone on the resistant Aspergillus niger spore. J. Hazard. Mater. 261, 155-162 (2013)

30. H. Rahimi, S. Roudbarmohammadi, H. Hamid Delavari, M. Roudbary, Antifungal effects of indolicidin-conjugated gold 
nanoparticles against fluconazole-resistant strains of candida albicans isolated from patients with burn infection. Int. J. Nanomed. 14, 5323-5338 (2019)

31. M. Kumari et al., An insight into the mechanism of antifungal activity of biogenic nanoparticles than their chemical counterparts. Pestic. Biochem. Physiol. 157, 45-52 (2019)

32. E.J.J. Mallmann, F.A. Cunha, B.N.M.F. Castro, A.M. Maciel, E.A. Menezes, P.B.A. Fechine, Atividade antifúngica de nanopartículas de prata obtidas por síntese verde. Rev. Inst. Med. Trop. Sao Paulo 57(2), 165-167 (2015)

33. S.W. Kim et al., An in vitro study of the antifungal effect of silver nanoparticles on oak wilt pathogen Raffaelea sp. J. Microbiol. Biotechnol. 19(8), 760-764 (2009)

34. P.A. Arciniegas-Grijalba, M.C. Patiño-Portela, L.P. MosqueraSánchez, J.A. Guerrero-Vargas, J.E. Rodríguez-Páez, ZnO nanoparticles (ZnO-NPs) and their antifungal activity against coffee fungus erythricium salmonicolor. Appl. Nanosci. 7(5), 225-241 (2017)

35. J. Pulit-Prociak, M. Banach 2013 Method of obtaining nanostructural zinc, iron, zirconium or copper oxides in the field of microwave radiation PL405172

36. J. Pulit-Prociak, M. Banach, Effect of process parameters on the size and shape of nano- and micrometric zinc oxide. Acta Chim. Slov. 63(2), 317-322 (2016)

37. Polish Standard PN-EN 1650:2019-12.

38. K. Saravanakumar, R. Chelliah, D. MubarakAli, D.H. Oh, K. Kathiresan, M.H. Wang, Unveiling the potentials of biocompatible silver nanoparticles on human lung carcinoma A549 cells and helicobacter pylori. Sci. Rep. 9(1), 1-8 (2019)

39. H.M. Fahmy et al., Coated silver nanoparticles: synthesis, cytotoxicity, and optical properties. RSC Adv. 9(35), 20118-20136 (2019)

40. A. Zaier, A. Meftah, A.Y. Jaber, A.A. Abdelaziz, M.S. Aida, Annealing effects on the structural, electrical and optical properties of $\mathrm{ZnO}$ thin films prepared by thermal evaporation technique. J. King Saud Univ.-Sci. 27(4), 356-360 (2015)

41. R. Dobrucka, J. Długaszewska, Biosynthesis and antibacterial activity of $\mathrm{ZnO}$ nanoparticles using Trifolium pratense flower extract. Saudi J. Biol. Sci. 23(4), 517-523 (2016)

42. E.A. Mwafy, A.A. Abd-Elmgeed, A.A. Kandil, I.A. Elsabbagh, M.M. Elfass, M.S. Gaafar, High UV-shielding performance of zinc oxide/high-density polyethylene nanocomposites. Spectrosc. Lett. 48(9), 646-652 (2015)

43. Y.C. Ching, A. Rahman, K.Y. Ching, N.L. Sukiman, C.H. Chuah, Preparation and characterization of polyvinyl alcohol-based composite reinforced with nanocellulose and nanosilica. BioResources 10(2), 3364-3377 (2015)

44. K. Wahyuningsih, E.S. Iriani, F. Fahma, Utilization of cellulose from pineapple leaf fibers as nanofiller in polyvinyl alcohol-based film. Indones. J. Chem. 16(2), 181-189 (2016)

45. S. Kumar, J. Koh, Physiochemical, optical and biological activity of chitosan-chromone derivative for biomedical applications. Int. J. Mol. Sci. 13(5), 6103-6116 (2012)

46. M.P. Das, P.R. Suganya, K. Prasad, Jv. Vijayalakshmi, R. Meena, Extraction and characterization of gelatin: a functional biopolymer. Int. J. Pharm. Pharm. Sci. 9(9), 239 (2017)

47. D. Mudgil, S. Barak, B.S. Khatkar, X-ray diffraction, IR spectroscopy and thermal characterization of partially hydrolyzed guar gum. Int. J. Biol. Macromol. 50(4), 1035-1039 (2012)

48. J.F. Mukerabigwi et al., Eco-friendly nano-hybrid superabsorbent composite from hydroxyethyl cellulose and diatomite. RSC Adv. 6(38), 31607-31618 (2016)

49. C. Nunes, A. Mahendrasingam, R. Suryanarayanan, Quantification of crystallinity in substantially amorphous materials by synchrotron X-ray powder diffractometry. Pharm. Res. 22(11), 1942-1953 (2005)
50. G. Nagaraju et al., Electrochemical heavy metal detection, photocatalytic, photoluminescence, biodiesel production and antibacterial activities of $\mathrm{Ag}-\mathrm{ZnO}$ nanomaterial. Mater. Res. Bull. 94, 54-63 (2017)

51. M.R. Jung et al., Validation of ATR FT-IR to identify polymers of plastic marine debris, including those ingested by marine organisms. Mar. Pollut. Bull. 127, 704-716 (2018)

52. Yuan Ming Huang 2012 Liquid crystals and related materials II. Trans Tech Publications

53. H. A. Gasteiger, W. RA, P. Starasser 2010 Polymer electrolyte fuel cells 10

54. I.Z. Selim, A.H. Basta, O.Y. Mansour, I.A. Aziza, Hydroxyethyl cellulose. ii. ir spectra and their relation with the dielectric properties of hydroxyethyl celluloses. Polym. Plast. Technol. Eng. 33(2), 161-174 (1994)

55. A. Kharazmi, N. Faraji, R.M. Hussin, E. Saion, W.M.M. Yunus, K. Behzad, Structural, optical, opto-thermal and thermal properties of ZnS-PVA nanofluids synthesized through a radiolytic approach. Beilstein J. Nanotechnol. 6(1), 529-536 (2015)

56. M.F. Queiroz, K.R.T. Melo, D.A. Sabry, G.L. Sassaki, H.A.O. Rocha, Does the use of chitosan contribute to oxalate kidney stone formation? Mar. Drugs 13(1), 141-158 (2015)

57. A.B.D. Nandiyanto, R. Oktiani, R. Ragadhita, How to read and interpret FTIR spectroscope of organic material. Indones. J. Sci. Technol. 4(1), 97 (2019)

58. Y. Seki, A. Altinisik, B. Demircioğlu, C. Tetik, Carboxymethylcellulose (CMC)-hydroxyethylcellulose (HEC) based hydrogels: synthesis and characterization. Cellulose 21(3), 1689-1698 (2014)

59. A.M.M. Essa, M.K. Khallaf, Biological nanosilver particles for the protection of archaeological stones against microbial colonization. Int. Biodeterior. Biodegrad. 94, 31-37 (2014)

60. N. Naghsh, M. Ghyasiyan, S. Soleimani, S. Torkan, Comparison between alcoholic eucalyptus and nano-silver as a new nanocomposition in growth inhibition of Aspergilus niger. Indian J. Sci. Technol. 5(S3), 2445-2447 (2015)

61. I. Zorraquín-Peña, C. Cueva, B. Bartolomé, M.V. Moreno-Arribas, Silver nanoparticles against foodborne bacteria. Effects at intestinal level and health limitations. Microorganisms 8(1), 132-156 (2020)

62. Z. Lu, K. Rong, J. Li, H. Yang, R. Chen, Size-dependent antibacterial activities of silver nanoparticles against oral anaerobic pathogenic bacteria. J. Mater. Sci. Mater. Med. 24(6), 1465-1471 (2013)

63. A. Ivask, I. Kurvet, K. Kasemets, I. Blinova, V. Aruoja, S. Suppi et al., Size-dependent toxicity of silver nanoparticles to bacteria, yeast, algae, crustaceans and mammalian cells in vitro. PLoS ONE 9(7), e102108 (2014)

64. C. Khurana, A.K. Vala, N. Andhariya, O.P. Pandey, B. Chudasama, Antibacterial activity of silver: the role of hydrodynamic particle size at nanoscale. J. Biomed. Mater. Res. - Part A 102(10), 3361-3368 (2014)

65. W. Lu, K. Yao, J. Wang, J. Yuan, Ionic liquids-water interfacial preparation of triangular $\mathrm{Ag}$ nanoplates and their shape-dependent antibacterial activity. J. Colloid Interface Sci. 437, 35-41 (2014)

66. S. Pal, Y.K. Tak, J.M. Song, Does the antibacterial activity of silver nanoparticles depend on the shape of the nanoparticle? A study of the gram-negative bacterium Escherichia coli. Appl. Environ. Microbiol. 73(6), 1712-1720 (2007)

67. N. Durán, M. Durán, M.B. de Jesus, A.B. Seabra, W.J. Fávaro, G. Nakazato, Silver nanoparticles: a new view on mechanistic aspects on antimicrobial activity. Nanomed. Nanotechnol. Biol. Med. 12(3), 789-799 (2015)

68. J.S. Kim, E. Kuk, K.N. Yu, J.H. Kim, S.J. Park, H.J. Lee et al., Antimicrobial effects of silver nanoparticles. Nanomed. Nanotechnol. Biol. Med. 3(1), 95-101 (2007) 
69. S.S. Hosseini, E. Ghaemi, F. Koohsar, Influence of $\mathrm{ZnO}$ nanoparticles on Candida albicans isolates biofilm formed on the urinary catheter. Iran. J. Microbiol. 10(6), 424-432 (2018)

70. S. Talal, F.A. Abbas, Effect of zinc oxide nanoparticles on Candida albicans of human saliva (in vitro study). Russ. Fed. Eur. J. Med. 10(4), 235-244 (2015)

71. S. Gulla, D. Lomada, V.V.S.S. Srikanth, M.V. Shankar, K.R. Reddy, S. Soni, M.C. Reddy, Recent advances in nanoparticlesbased strategies for cancer therapeutics and antibacterial applications. Methods Microbiol. 46, 255-293 (2019)

72. P. Sharma, S. Pant, V. Dave, K. Tak, V. Sadhu, K.R. Reddy, Green synthesis and characterization of copper nanoparticles by Tinospora cardifolia to produce nature-friendly copper nano-coated fabric and their antimicrobial evaluation. J. Microbiol. Methods 160, 107-116 (2019)

73. K.R. Reddy, P.A. Reddy, C.V. Reddy, N.P. Shetti, B. Babu, K. Ravindranadh, S. Naveen, Functionalized magnetic nanoparticles/ biopolymer hybrids: synthesis methods, properties and biomedical applications. Methods Microbiol. 46, 227-254 (2019)
74. K. Kannan, D. Radhika, K.K. Sadasivuni, K.R. Reddy, A.V. Raghu, Nanostructured metal oxides and its hybrids for photocatalytic and biomedical applications. Adv. Colloid Interface Sci. 281, 102178 (2020)

75. A. Misra, S. Jain, D. Kishore, V. Dave, K.R. Reddy, V. Sadhu, J. Dwivedi, S. Sharma, A facile one pot synthesis of novel pyrimidine derivatives of 1,5-benzodiazepines via domino reaction and their antibacterial evaluation. J. Microbiol. Methods 163, 105648 (2019)

76. A. Nagaraja, M.D. Jalageri, Y.M. Puttaiahgowda, K.R. Reddy, A.V. Raghu, A review on various maleic anhydride antimicrobial polymers. J. Microbiol. Methods 163, 105650 (2019)

Publisher's Note Springer Nature remains neutral with regard to jurisdictional claims in published maps and institutional affiliations. 